\title{
Sodium Excretion Rate
}

National Cancer Institute

\section{Source}

National Cancer Institute. Sodium Excretion Rate. NCI Thesaurus. Code C150823.

A determination of the amount of sodium being excreted in a biological specimen over a defined period of time. 